\title{
Casting properties of ASTM A128 Gr: E1 steel modified with Mn-alloying and titanium ladle
} treatment

\author{
*Uğur Gürol ${ }^{1,2}$, Erdal Karadeniz ${ }^{3}$, Ozan Çoban ${ }^{4}$, Süleyman Can Kurnaz ${ }^{2}$ \\ 1. Gedik Welding Company, Ankara Caddesi, 34906, Istanbul, Turkey \\ 2. Sakarya University, Engineering Faculty, Department of Metallurgical \& Materials Engineering, Esentepe Campus, 54187, Sakarya, Turkey \\ 3. Sakarya University, Engineering Faculty, Department of Mechanical Engineering, Esentepe Campus, 54187, Sakarya, Turkey \\ 4. Istanbul Gedik University, Engineering Faculty, Department of Metallurgical \& Materials Engineering, 34876, Istanbul, Turkey
}

\begin{abstract}
This work aims to produce a high manganese steel with more refined austenite grains and better wear resistance without sacrificing the toughness and tensile properties by Mn alloying and Ti ladle treatment in comparision to ASTM A128 Gr. E1 steel (1.0C-13Mn) that is mostly used in the mining industry. The 1.0C-17Mn$x \mathrm{Ti}$ alloys ( $x=0,0.05$ and 0.1 , in wt.\%) were prepared. A relationship was established between the microstructures and mechanical properties of the as-cast and solution annealed alloys. Increasing Ti content increases the stable $\mathrm{Ti}(\mathrm{CN})$ phase on and beside the grain boundaries and decreases up to $37 \%$ the austenite grain size of the ascast alloy with $0.10 \mathrm{wt}$ \% Ti. Correspondingly, after solution annealed, optimized titanium content $(0.05 \mathrm{wt} . \%)$ results in significant improvements in wear resistance, hardness, elongation, yield and tensile strengths by $44 \%$, $31 \%, 30 \%, 8 \%$ and $12 \%$, respectively, except $9 \%$ decrease in impact toughness compared to ASTM A 128 Gr. E1 steel without modification. These results show that $1.0 \mathrm{C}-17 \mathrm{Mn}-0.05 \mathrm{Ti}$ alloy can be used for parts exposed to high load wear and applied in conditions where relatively high tensile properties with sufficent ductility is needed.
\end{abstract}

Key words: high manganese steel; hadfield steel; ladle treatment; grain refinement; microstructure; mechanical properties

CLC numbers: TG142.25 Document code: A

Article ID: 1672-6421(2021)03-199-08

\section{Introduction}

High manganese austenitic steels which are also called Hadfield steels are most commonly used as wear materials in the mining industry due to their excellent wear resistance ${ }^{[1]}$. Improvement of wear resistance of these steels without decreasing other mechanical properties is very important. The basic chemical composition of Hadfield steel includes 1.0wt.\%-1.4wt.\% carbon and $10 \mathrm{wt} . \%-14 \mathrm{wt} . \%$ manganese in a 1:10 ratio ${ }^{[2]}$. These steels are classified within different groups in ASTM A128 Standard (Specification for Steel Castings, Austenitic Manganese) and mostly Mo-containing grade (ASTM A128 Gr. E1) is used for the heavy section casting parts due to its high resistance to carbide

\section{*Uğur Gürol}

Male, Ph. D. His research interests mainly focus on steel making and heat treatment. $\mathrm{He}$ is experienced in various non-destructive inspection techniques in accordance with EN and ASME, such as visual inspection, ultrasonic inspection, and destructive tests like tensile test, Charpy impact test, etc.

E-mail: ugur.gurol@yahoo.com

Received: 2021-01-08; Accepted: 2021-03-17 brittleness during reheating of the casting parts. In this way, the possibility of cracking during cutting and welding repair is decreased and consequently providing easier flame cutting of gates and feeders in foundry conditions ${ }^{[3]}$. These steels must be suitably heat treated to achieve high toughness and ductility. This heat treatment process must consist of uniformly heating the castings to a temperature applicable for the grade of steel produced, at least $1,000{ }^{\circ} \mathrm{C}$, holding until the temperature is uniform throughout, and quenching in water.

Titanium, niobium, vanadium and aluminium are among the common alloying additions for grain refining in the steels ${ }^{[4-8]}$. Among them, titanium nitride (TiN), characterized as the most effective grain growth inhibiting microalloy, precipitates at temperatures above $1,323 \mathrm{~K}\left(1,050{ }^{\circ} \mathrm{C}\right){ }^{[9]}$. This assertion is accepted as a consequence of the higher volume fraction provided by the lower solubility of TiN in austenite compared to other carbides and nitrides. High-temperature precipitation of TiN, however, can also be harmful to its grain refining potential due to precipitate growth 
and coarsening at elevated temperatures ${ }^{[10]}$.

Zhuang et al. ${ }^{[4]}$ studied the effect of various Ti content on the microstructure and mechanical properties of chromecontaining high manganese steel in as-cast condition. They reported that the $\mathrm{Ti}$ alloying which refined the as-cast grain structure also resulted in the formation of inclusion and a lot of dispersed particles that enhanced hardness and wear resistance. However, as mentioned in our previous study, high manganese austenitic steels are too brittle in the as-cast condition due to their secondary precipitations, such as carbide and phosphide eutectic along the grain boundaries, which limit their application in the mining industry which requires high toughness and ductility with the combination of high wear resistance ${ }^{[1]}$. In addition, the titanium content was limited to $0.017 \mathrm{wt} . \%$.

Najafabadi et al. ${ }^{[12]}$ also investigated the effect of titanium addition (up to $0.6 \mathrm{wt} . \%$ ) on the wear resistance of Hadfield steel and they found that $0.6 \mathrm{wt} . \% \mathrm{Ti}$ addition significantly increased the wear resistance. However, they didn't study the effect of various loads during wear testing. It is very significant to investigate work hardening and wear rate according to load in order to integrate the experimental behavior of Hadfield steel to industrial use. In addition, there is no extensive research on thick section cast parts in the literature. Fully austenite microstructure without undissolved or precipitated carbides in thick-walled casting parts cannot be produced easily ${ }^{[13]}$. Therefore, the current work aims to produce a high manganese steel (wall thickness $t>50 \mathrm{~mm}$ ) with more refined grains and better wear resistance in comparasion to reference steel ASTM A128 Grade E1 without sacrificing the toughness and tensile properties by Mn alloying and Ti ladle treatment.

\section{Materials and methods}

The alloys were obtained with an industrial-scale induction furnace that had a maximum capacity of $3,000 \mathrm{~kg}$ in a steel foundry located in Istanbul, Turkey. The corundum-based neutral lining was used in a melting furnace to prevent the attacking of manganese oxides. The required molten steel was prepared with classified steel scraps, standard silicon, lowcarbon ferro-manganese, high-carbon ferro-molibdenum and recycled manganese steel products. When the raw material was fully melted, the molten steel was transferred to the pouring ladle which was pre-heated at $900{ }^{\circ} \mathrm{C}$. Before the tapping, the $\mathrm{Fe}$-Ti particles covered with steel scraps were placed at the bottom of the ladle. The compositions of the alloys are given in Table 1

Table 1: Chemical compositions of alloys (wt.\%)

$\begin{array}{ccccccccccc}\text { Alloy } & \text { C } & \text { Mn } & \text { Si } & \text { Mo } & \text { P } & \text { S } & \text { Ti } & \text { Fe } \\ \text { ASTM 128 Gr. E1 } & 1.00 & 13.11 & 0.53 & 1.15 & 0.035 & 0.003 & 0.006 & \text { Bal. } \\ \text { 1.0C-17Mn } & 1.00 & 17.11 & 0.53 & 1.16 & 0.037 & 0.002 & 0.008 & \text { Bal. } \\ \text { 1.0C-17Mn-0.05Ti } & 1.01 & 17.18 & 0.58 & 1.17 & 0.036 & 0.004 & 0.046 & \text { Bal. } \\ \text { 1.0C-17Mn-0.10Ti } & 1.01 & 17.09 & 0.55 & 1.16 & 0.037 & 0.004 & 0.094 & \text { Bal. }\end{array}$

The chemical analysis was performed by the ARL optical emission spectrometer according to the ASTM E2209 standard from chilled samples taken from the inside of the transferred ladle. Finally, test coupons with dimensions of $60 \mathrm{~mm} \times 60 \mathrm{~mm}$ $\times 300 \mathrm{~mm}$, as shown in Fig. 1, were cast into a chromite sand mold at the pouring temperatures of $1,440{ }^{\circ} \mathrm{C}$ and $1,450{ }^{\circ} \mathrm{C}$, respectively. The alloys were solution annealed in an oxygencontrolled custom-built automatic heat treatment furnace with a specific heat treatment process which included heating the castings up to $650{ }^{\circ} \mathrm{C}$ and holding for $3 \mathrm{~h}$. This mid-process was performed to prevent internal cracking formation and decrease in the length and amount of the carbide plates in the as-cast structure ${ }^{[14]}$. Then, the samples were heated to $1,100^{\circ} \mathrm{C}$ at the rate of $1.67{ }^{\circ} \mathrm{C} \cdot \mathrm{min}^{-1}$ and held for $3 \mathrm{~h}$. Finally, they were quenched in an industrial quenching tank with $90 \mathrm{t}$ of water at $27^{\circ} \mathrm{C}$. It is strongly recommended that the water temperature before quenching be around $25{ }^{\circ} \mathrm{C}-28{ }^{\circ} \mathrm{C}$ and the final water temperature after solution annealing should never be above $35^{\circ} \mathrm{C}$ in order to prevent carbide precipitation through all thick-walled sections ${ }^{[15]}$. During the quenching, compressed air was fed into the quenching tank for improving the circulation of the water. As a result, the final water temperature was kept steady at $27^{\circ} \mathrm{C}$ in this study.

Metallographic examination was performed according to ASTM E3 (metallographic sample preparation) and ASTM E407 (metal micro-etching) standards. The sectioned specimens for metallography which were taken from the middle of the casting samples as shown in Fig. 1(c) were ground, polished and etched with $4 \mathrm{wt} . \%$ nital solution for $10 \mathrm{~s}$. The microstructures of the as-cast and solution annealed specimens were characterized using an optical microscope (OM, Olympus PME Tokyo) and a scanning electron microscope (SEM, FEI Quanta FEG 450) equipped with energy dispersive spectrometry (EDS, EDAX Octane Plus). The average grain size of each alloy was measured using the intercept method according to the ASTM standard E112 (standard test methods for determining average grain size) by using Image-J software (version $1.51 \mathrm{k}$ ), which was also used to determine the carbide volume fraction of the alloys. The amount of the precipitated phases was calculated using ThermoCalc simulation software.

The surface hardness of the samples was measured using a Brinell hardness tester at room temperature in compliance with ASTM E10 standard. Tensile testing was performed with an Instron test machine, Model 300 LX, employing an average 

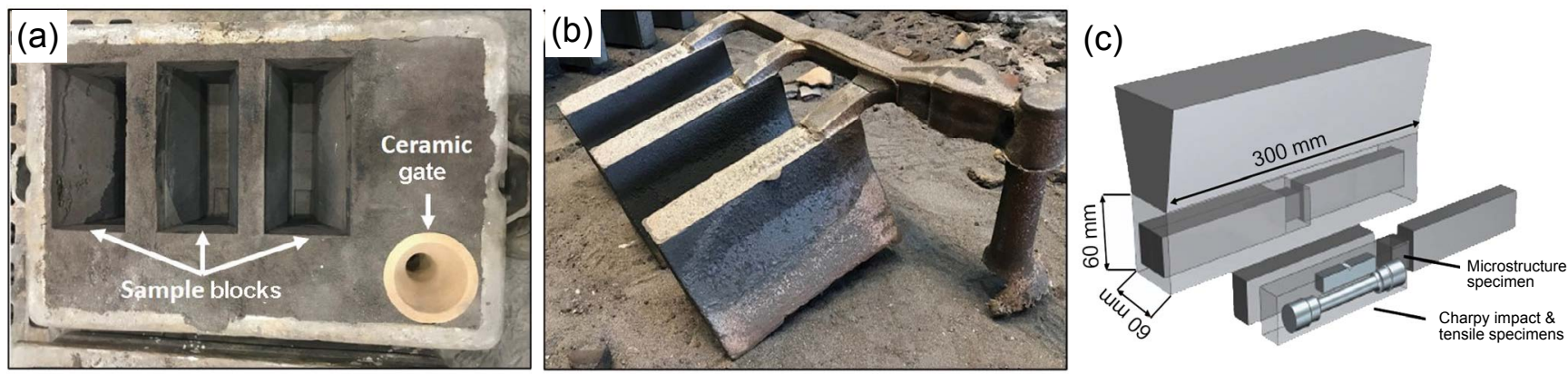

Fig. 1: Chromite sand mold before casting (a), test coupons after casting and shake out (b), and location of test specimens (c)

of three specimens for each sample with respect to ASTM E8/ E8M. The impact testing was carried out on a specimen of $10 \mathrm{~mm} \times 10 \mathrm{~mm} \times 55 \mathrm{~mm}$ at room temperature, using a $300 \mathrm{~J}$ capacity test machine, with the Charpy V-notch test method according to ASTM E23. The ball-on-disc wear testing was carried out in accordance with ASTM G99 standard. The tests were performed at room temperature with a $10 \mathrm{~mm}$ diameter alumina ball as the counter body. The weight loss of each sample was measured under $2.5 \mathrm{~N}, 5 \mathrm{~N}, 10 \mathrm{~N}$ and $15 \mathrm{~N}$ loads at $0.2 \mathrm{~m} \cdot \mathrm{s}^{-1}$ sliding speed with $500 \mathrm{~m}$ sliding distance.

\section{Results and discussion}

In order to see the phases and the amounts of precipitates which could appear during solidification of alloys between 400-1,800 ${ }^{\circ} \mathrm{C}$, Thermo-Calc software (TCFE7 database) was used and the results are given in Fig. 2, and the precipitation temperatures of these phases in $1.0 \mathrm{C}-17 \mathrm{Mn}-0.05 \mathrm{Ti}$ alloy are given in Table 2. It can be seen that with the decrease in temperature, $\mathrm{MnS}, \mathrm{M}_{7} \mathrm{C}_{3}$ and $\mathrm{M}_{3} \mathrm{C}$ (cementite) phases are precipitated successively. After the formation of austenite, firstly, $\mathrm{MnS}$ starts to form at $1,266{ }^{\circ} \mathrm{C}$, followed by precipitation of partial primary carbides among the austenite phase at $868^{\circ} \mathrm{C}$.
Immediately afterwards, cementite precipitates at $776{ }^{\circ} \mathrm{C}$ and perlite transformation (BCC_A2) occurs at $568^{\circ} \mathrm{C}$.

Compared with the 1.0C-17Mn alloy [Fig. 2(a)], with the addition of titanium, stable $\mathrm{Ti}(\mathrm{CN})$ phase is formed above the solidification temperature $\left(1,495^{\circ} \mathrm{C}\right)$ [Fig. 2(b)] because titanium has higher nitrogen affinity than the other elements. The amount of the $\mathrm{Ti}(\mathrm{CN})$ precipitate keeps increasing up to the temperature $\left(1,255^{\circ} \mathrm{C}\right)$ at which solidification is completed. With the further decrease of temperature, the amount of precipitation remains constant as the diffusion of the atoms in the Ti(CN) particles is blocked by the solidified austenite phase.

\subsection{Microstructural characterization of as-cast alloys}

Figure 3 illustrates the effect of manganese and titanium content on the as-cast microstructure of the alloys. It shows that all the as-cast alloys have an austenite matrix surrounded by alloyed cementite $(\mathrm{FeMn})_{3} \mathrm{C}$ in the lamellar form, and molybdenum carbides $(\mathrm{MoC})$ distribute in elongated or spherical form in the center of lamellar cementite ${ }^{[11]}$. The volume fractions of the carbides developed in the as-cast alloys were measured by Image-J software and are listed in Table 3. There is no significant difference in the amount of carbide in the four
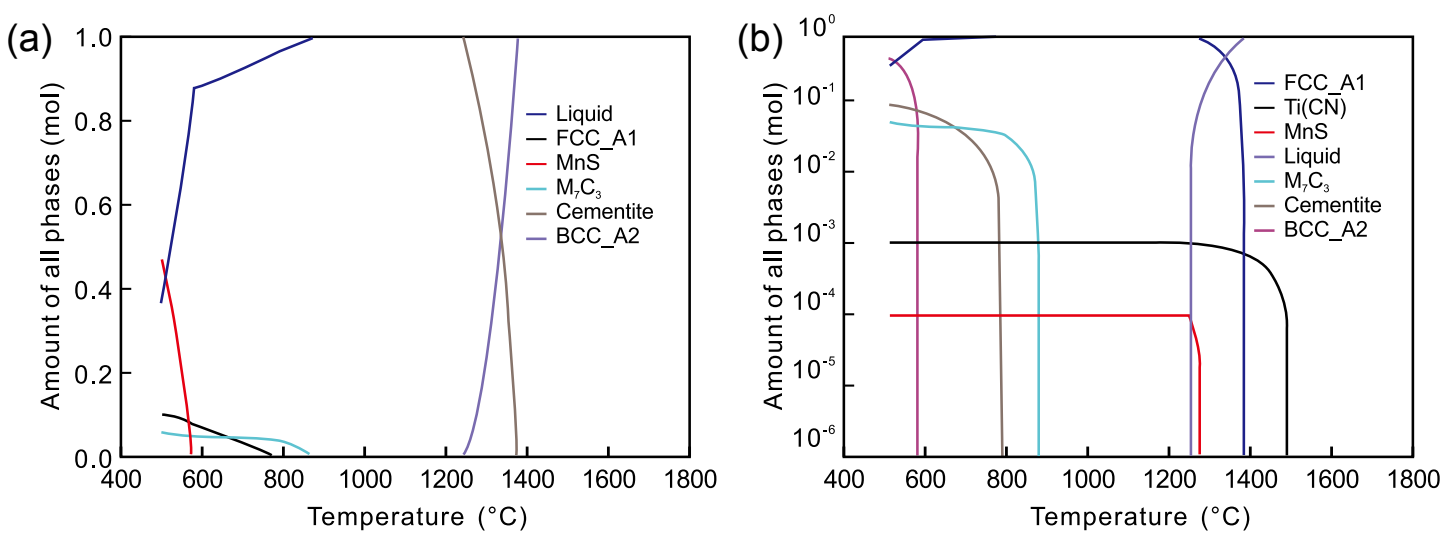

Fig. 2: Predicted phase precipitation diagram of alloys in a temperature range of $400-1,800{ }^{\circ} \mathrm{C}$ : (a) $1.0 \mathrm{C}-17 \mathrm{Mn}$ and (b) 1.0C-17Mn-0.05Ti

Table 2: Phase precipitation temperatures of $1.0 \mathrm{C}-17 \mathrm{Mn}-0.05 \mathrm{Ti}$ alloy in a temperature range of $400-1,800{ }^{\circ} \mathrm{C}$

\begin{tabular}{rcccccc} 
Ti(CN) & Liquidus & Solidus & Mns & $\mathrm{M}_{7} \mathrm{C}_{3}$ & Cementite & BCC-A2 \\
\hline $1,495{ }^{\circ} \mathrm{C}$ & $1,380^{\circ} \mathrm{C}$ & $1,255^{\circ} \mathrm{C}$ & $1,266{ }^{\circ} \mathrm{C}$ & $868^{\circ} \mathrm{C}$ & $776{ }^{\circ} \mathrm{C}$ & $568{ }^{\circ} \mathrm{C}$
\end{tabular}



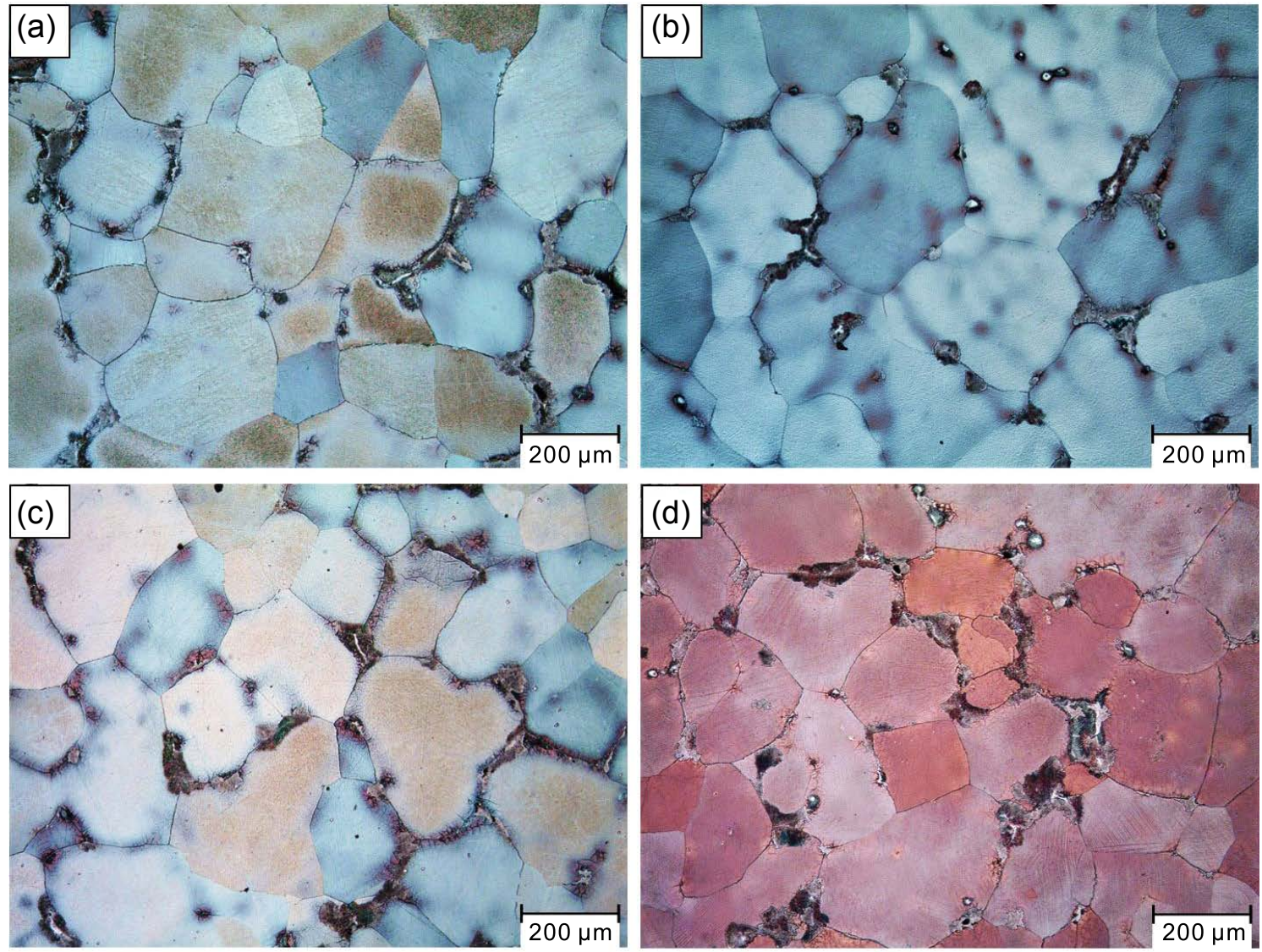

Fig. 3: Optical micrographs showing the as-cast microstructure of alloys: (a) ASTM A128 Gr. E1, (b) $1.0 \mathrm{C}-17 \mathrm{Mn}$, (c) 1.0C-17Mn-0.05Ti, (d) 1.0C-17Mn-0.10Ti

Table 3: Volume fraction of carbides and austenite in as-cast alloys (\%)

\begin{tabular}{|c|c|c|c|c|}
\hline & ASTM A128 Gr. E1 & $1.0 \mathrm{C}-17 \mathrm{Mn}$ & $1.0 \mathrm{C}-17 \mathrm{Mn}-0.05 \mathrm{Ti}$ & $1.0 \mathrm{C}-17 \mathrm{Mn}-0.10 \mathrm{Ti}$ \\
\hline Carbides & $7.5 \pm 1.7$ & $6.1 \pm 2.5$ & $7.48 \pm 3.3$ & $9.06 \pm 2.5$ \\
\hline Austenite & Bal. & Bal. & Bal. & Bal. \\
\hline
\end{tabular}

as-cast alloys. The SEM microstructures shown in Fig. 4 reveal that $\mathrm{Ti}(\mathrm{CN})$ precipitation ranging $2-5 \mu \mathrm{m}$ occurs on or beside the grain boundaries, indicating the predicted equilibrium composition in Fig. 2 is in good agreement with the experimental measurements at ambient temperature. The $\mathrm{Ti}(\mathrm{CN})$ precipitation in the alloy with $0.05 \% \mathrm{Ti}$ addition is randomly dispersed, however increasing $\mathrm{Ti}$ content to $0.10 \%$ results in the segregation of $\mathrm{Ti}(\mathrm{CN})$ beside the grain boundaries. Additionally, EDS results given in Figs. 4(b) and (d) show that phosphorus is concentrated at austenite grain boundries and forms $(\mathrm{FeMn})_{3} \mathrm{P}$ eutectic ${ }^{[16]}$. The new Ti(CN) interfaces acted as the nuclei sites for phosphorus segregation ${ }^{[17]}$.

Carbon is an element that diffuses rapidly at high temperatures, so when the liquid metal contacts with the ferrotitanium (FeTi) additives, carbon tends to diffuse rapidly towards the low carbon areas of FeTi. Likewise, the added ferro-titaniums (FeTi) begin to dissolve in the molten metal, allowing the titaniums to diffuse freely. Free titanium and carbon atoms react on the surface of FeTi particles to form primary $\mathrm{TiC}$ particles. Immediately afterwards, due to thermal convection, primary $\mathrm{TiC}$ particles diffuse through the molten steel where the temperature is high, allowing diffusion of nitrogen atoms. Meanwhile, the transformation of $\mathrm{TiC}$ particles into $\mathrm{Ti}(\mathrm{CN})$ particles takes place ${ }^{[18]}$. The lattice type of titanium is hexagonal closed packed and can form stable compounds with nitrogen, oxygen and carbon ${ }^{[4,19]}$. According to the heterogeneous nucleation theory proposed by Tumbell et al ${ }^{[20]}$, a phase with a high melting point can be used as a heterogeneous nucleation when the incompatibility between two phases is less than $12 \%$. In addition, the degree of incompatibility of titanium nitride with $\gamma$-Fe is known to be $10.61 \%^{[4]}$. For all these reasons, the high melting point compounds formed by $\mathrm{Ti}, \mathrm{C}$, and $\mathrm{N}$ act as heterogeneous nuclei during the solidification of the molten metal. As it can be seen in Table 4, compared to the $1.0 \mathrm{C}-17 \mathrm{Mn}$ sample, the addition of $0.05 \mathrm{Ti}$ and $0.10 \mathrm{Ti}$ resulted in a reduction of $26 \%$ and $37 \%$, respectively, in the grain size of the as-cast alloys. 

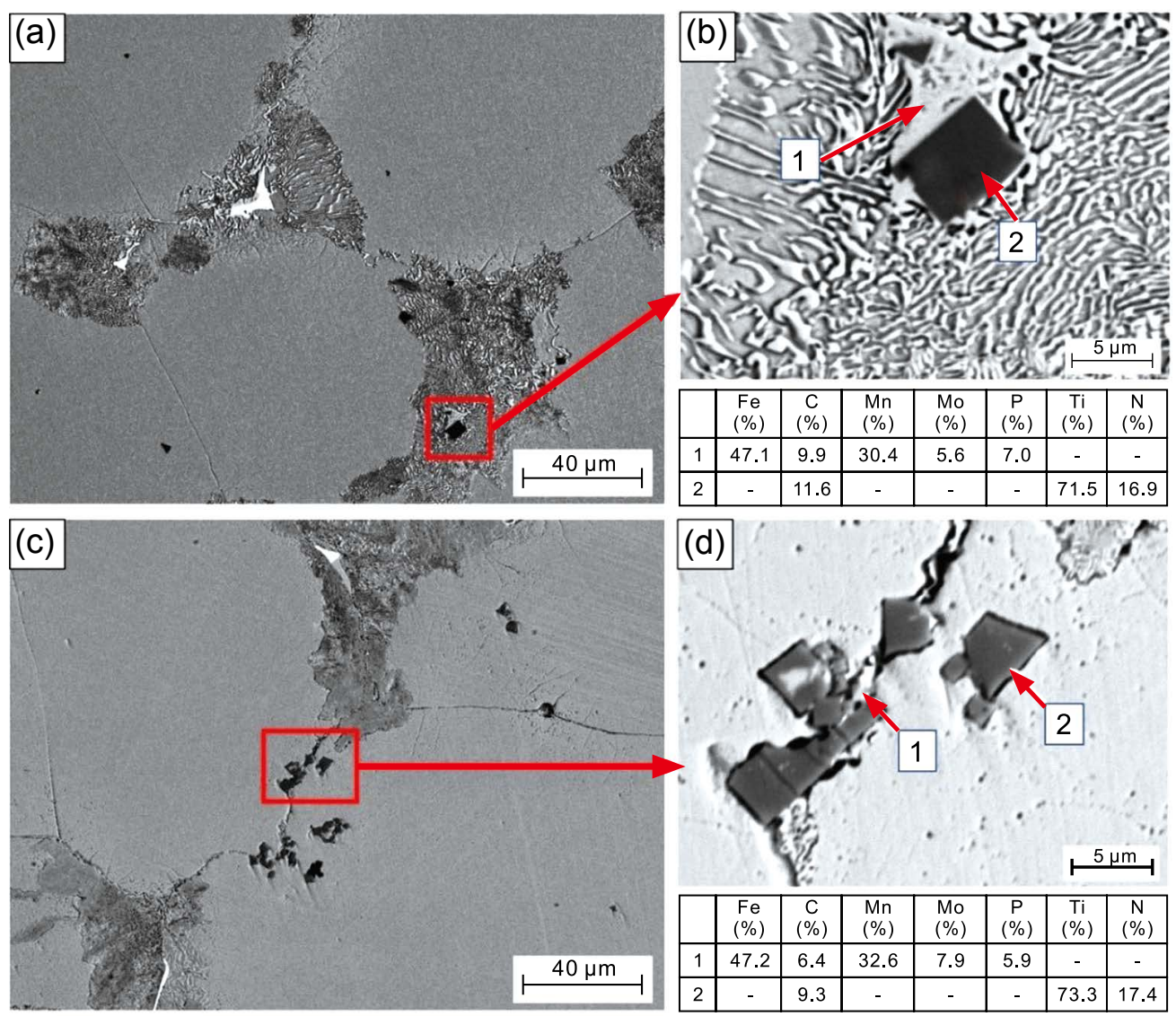

Fig. 4: SEM micrograph (BSE mode) and EDS results of as-cast alloys: (a, b) 1.0C-17Mn-0.05Ti and (c, d) 1.0C-17Mn-0.10Ti

Table 4: Grain size of alloys in as-cast and solution annealed condition

\begin{tabular}{cccc} 
Alloys & As-cast & Solution annealed & Grain coarsening (\%) \\
\hline ASTM A128 Gr. E1 & $172 \pm 11 \mu \mathrm{m}$ & $215 \pm 10 \mu \mathrm{m}$ & $\sim 25$ \\
1.0C-17Mn & $243 \pm 20 \mu \mathrm{m}$ & $338 \pm 26 \mu \mathrm{m}$ & $\sim 39$ \\
$1.0 \mathrm{C}-17 \mathrm{Mn}-0.05 \mathrm{Ti}$ & $179 \pm 10 \mu \mathrm{m}$ & $187 \pm 5 \mu \mathrm{m}$ & $\sim 4$ \\
$1.0 \mathrm{C}-17 \mathrm{Mn}-0.10 \mathrm{Ti}$ & $152 \pm 8 \mu \mathrm{m}$ & $161 \pm 5 \mu \mathrm{m}$ & $\sim 5$
\end{tabular}

\subsection{Microstructural characterization of solution annealed alloys}

Figures 5 and 6 show the microstructures of the solution annealed alloys. Ti-free alloys reveals a fully austenitic microstructure while Ti-containing alloys show an austenitic structure including $\operatorname{Ti}(\mathrm{CN})$ particles, especially on and beside the grain boundaries. This indicates that except stable $\mathrm{Ti}(\mathrm{CN})$ particles, all the secondary precipitations such as lamellar carbides and phosphide eutectics are succesfully dissolved into the austenite matrix with solution annealing heat treatment and rapid quenching. Additionally, solution annealing resulted in the grain coarsening of the alloys as can be seen in Table 4. However, Ti-containing alloys show a very small degree of grain coarsening compared to Ti-free alloys, because the precipitates act as pinning particles and prevent grain growth.

\subsection{Mechanical properties}

Figure 7 shows the mechanical properties of as-cast and solution annealed alloys. All the as-cast alloys show poor ductility and ultimate tensile strength due to the carbide and $\mathrm{Ti}(\mathrm{CN})$ precipitations along the grain boundaries [Fig. 7(a, c)]. These secondary precipitations cause stress occurrence and crack initation, which resulting in brittle fracture. The degree of brittleness in austenitic manganese steels depends on the degree of grain boundary coverage by the secondary phases. In this respect, intergranular carbides play a key role but other embrittling phases such as phosphide eutectic, $\operatorname{Ti}(\mathrm{CN})$ precipitates and microporosity also are involved ${ }^{[21]}$. Therefore, the highest ductility and tensile properties are obtained with 1.0C-17Mn alloy in as-cast condition. Morever, increased manganese and titanium increases the hardness of all as-cast alloys [Fig. 7(c)]. The highest hardness and yield strength 

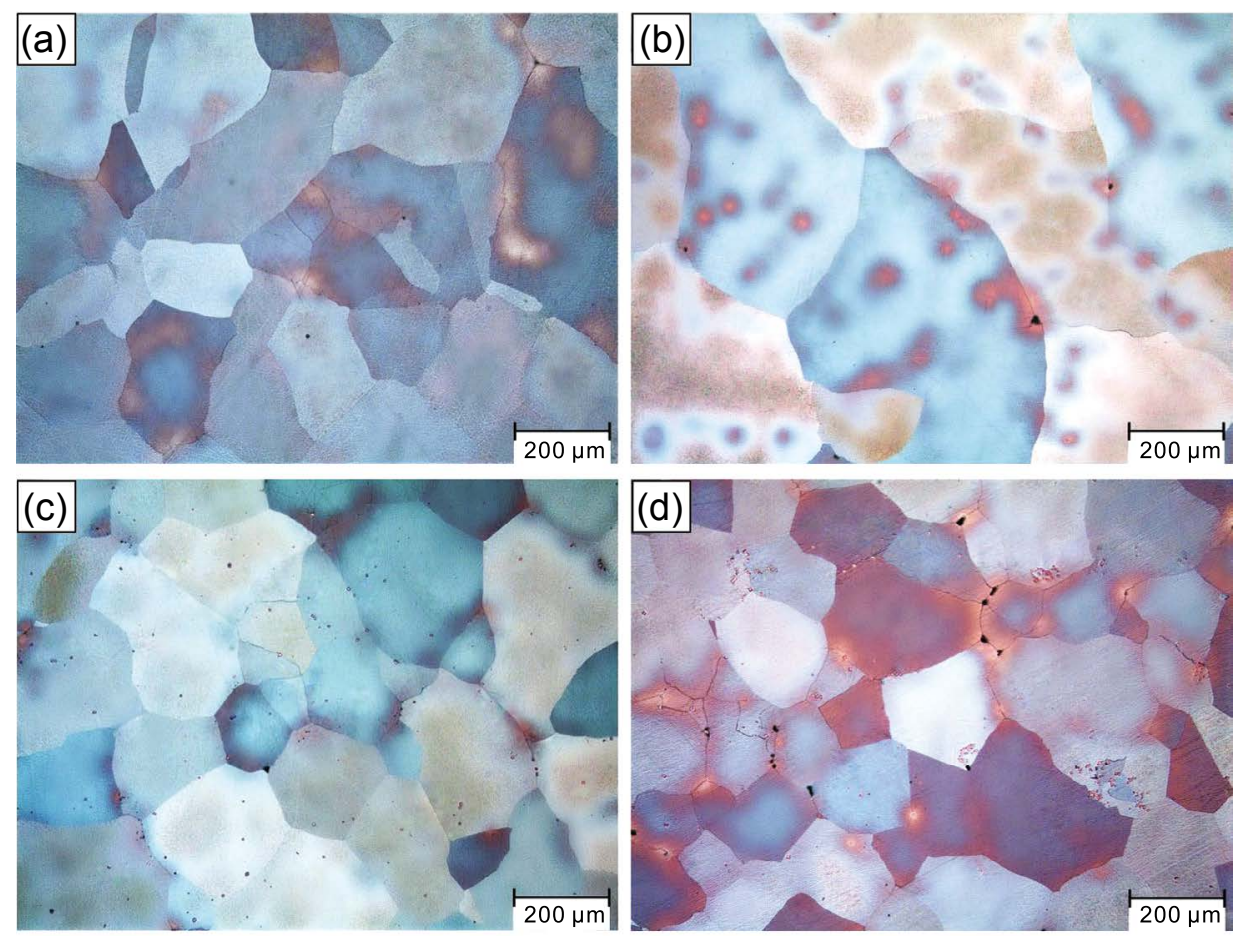

Fig. 5: Optical micrographs showing the solution annealed microstructure of alloys: (a) ASTM A128 Gr. E1; (b) 1.0C-17Mn; (c) 1.0C-17Mn-0.05Ti; 1.0C-17Mn-0.10Ti
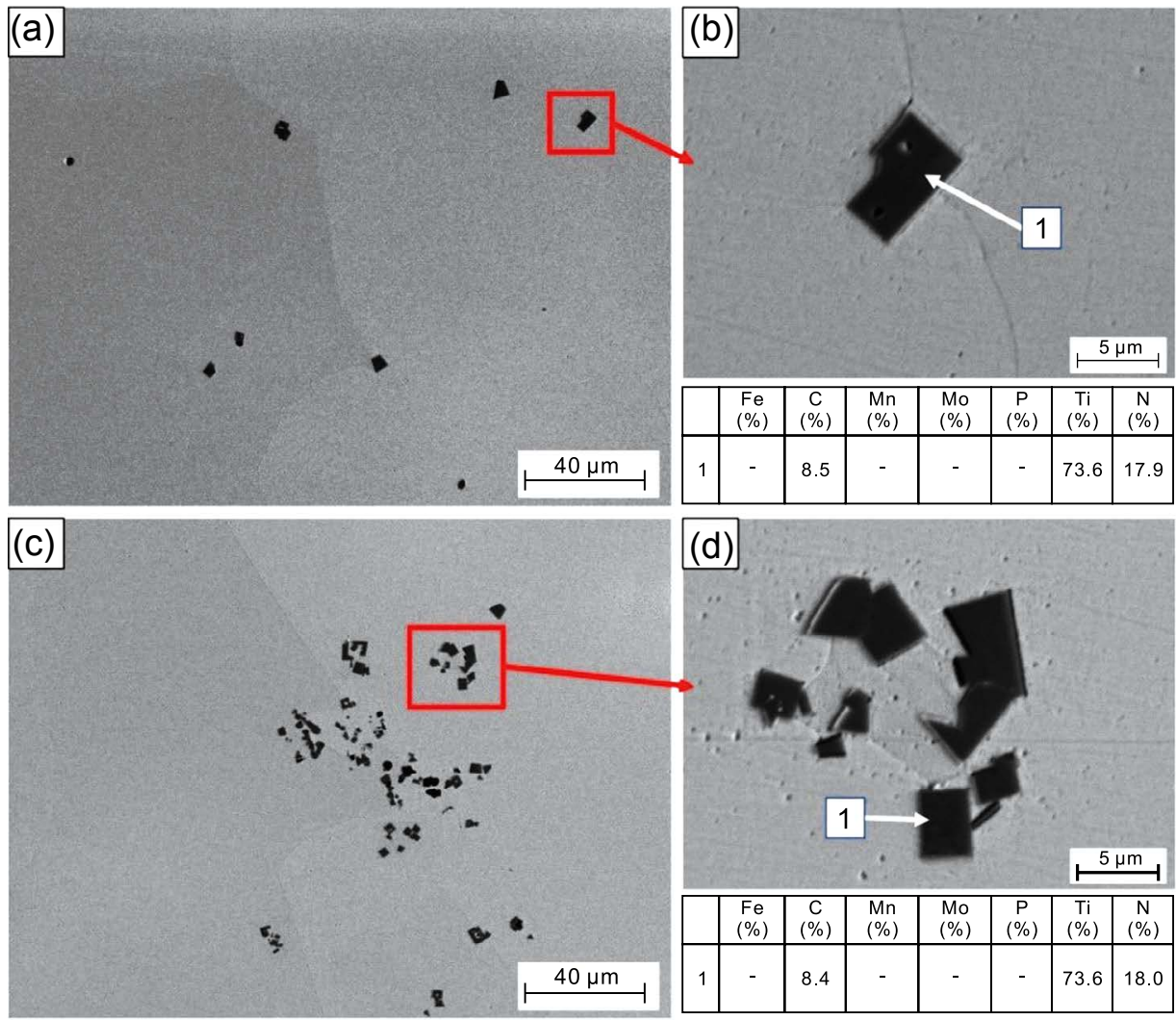

Fig. 6: SEM micrograph (BSE mode) and EDS results of alloys in solution annealed condition: (a, b) 1.0C-17Mn-0.05Ti, (c, d) 1.0C-17Mn-0.10Ti

are obtained with $1.0 \mathrm{C}-17 \mathrm{Mn}-0.10 \mathrm{Ti}$ alloy due to the smaller grain size in comparison to other as-cast alloys. An increase of $4 \%$ in the yield strength of as-cast alloy is obtained when the austenite grain size is reduced from $243 \pm 20 \mu \mathrm{m}$ without Ti to $152 \pm 8 \mu \mathrm{m}$ with $0.10 \mathrm{wt} . \%$ Ti inoculation (Table 4 ), which is in good agreement with the grain boundary strengthening theory described by the Hall-Petch effect ${ }^{[22]}$.

The hardness of solution annealed alloys show a similar trend with their as-cast states, but with higher hardness values and excellent plastic deformation above $50 \%$. This can be 
(a)

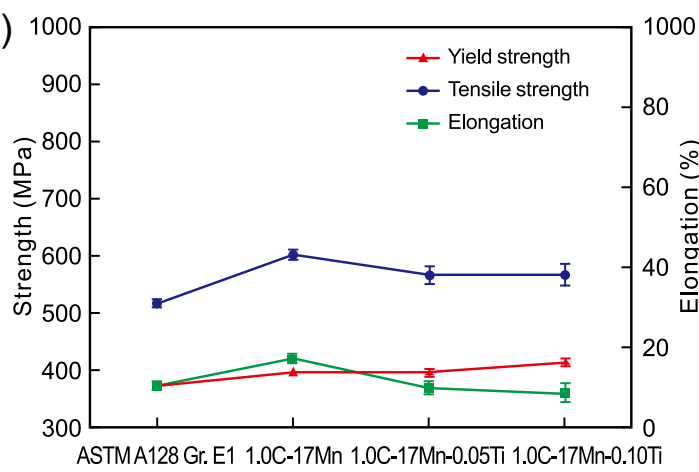

(c)

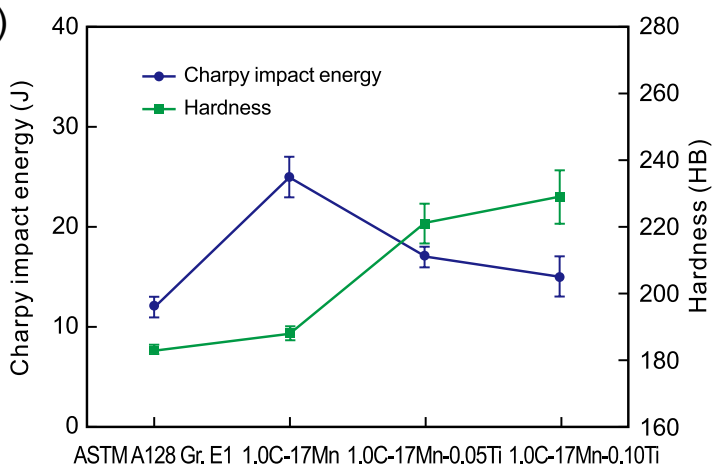

(b)

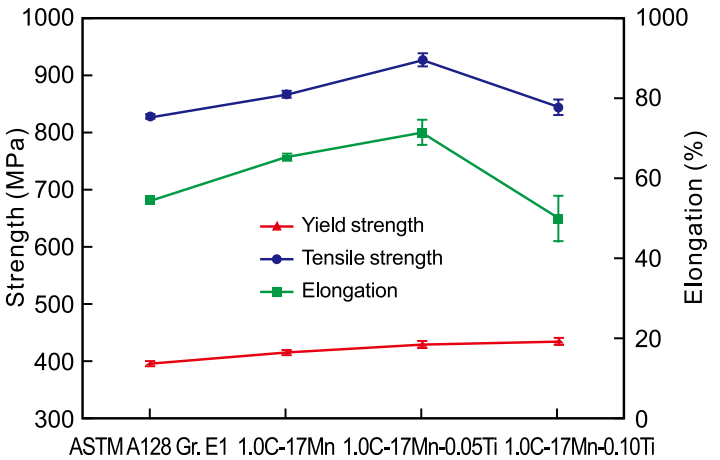

(d)

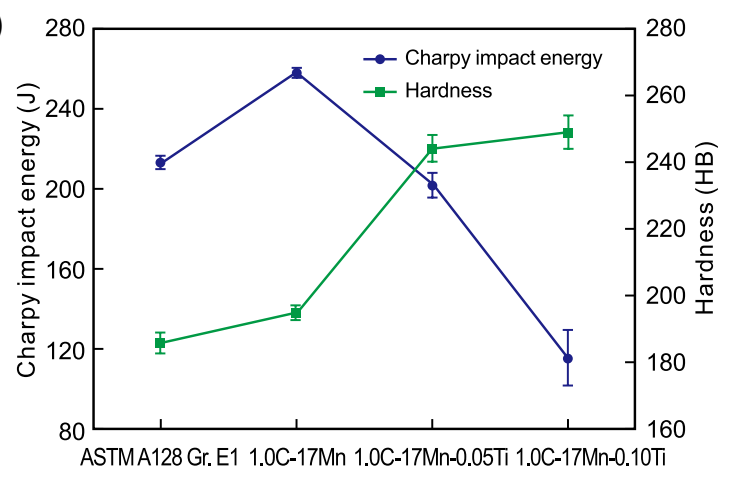

Fig. 7: Comparison of mechanical properties of as-cast $(a, c)$ and solution annealed (b, d) alloys

well explained with solid solution strengthening caused by the carbide resolution at the grain boundaries. In addition, increased $\mathrm{Mn}$ content from $13 \mathrm{wt} . \%$ to $17 \mathrm{wt} . \%$ in solution annealed condition increases the stacking fault energy and results in increment of shear stress needed for sliding ${ }^{[23]}$. This leads to the increase of ultimate tensile strength, elongation and Charpy impact energy, in 1.0C-17Mn alloy by 5\%, 20\% and $21 \%$, respectively, compared to ASTM A128 Gr. E1 steel. On the other hand, formation of well-dispersed $\mathrm{Ti}(\mathrm{CN})$ particles with $0.05 \mathrm{Ti}$ addition can refine the austenite grain size and increase the dislocation density and hereby strongly hinder the movement of dislocations and work hardening ability. The combination of grain boundry strengthening, solid solution strengthening and dispersion strenthening results in an increase in elongation, hardness, yield and tensile strengths, in as-cast $1.0 \mathrm{C}-17 \mathrm{Mn}-0.05 \mathrm{Ti}$ alloy by $30 \%, 31 \%, 8 \%$ and $12 \%$, respectively, in comparison to ASTM A128 Gr. E1 steel. However, the Charpy impact energy linearly decreases with Ti addition. Smaller grains are usually considered to be a significant approach to attain better toughness in bodycentered cubic (BCC) steels. Plastic deformation mechanism is only dislocation slip in BCC steels. However, twinning, which greatly depends on grain size, is the main secondary deformation mechanism in face-centered cubic (FCC) austenitic manganese steels besides dislocation slip ${ }^{[24]}$. Due to the twinning effect being more active in greater grain size ${ }^{[18,25]}$, Charpy impact energy for the alloy with $0.05 \mathrm{wt} . \% \mathrm{Ti}$ decreases $9 \%$ in comparation to ASTM A128 Gr. E1 steel. However, $\mathrm{Ti}(\mathrm{CN})$ particles that formed with $0.10 \mathrm{wt} . \%$ Ti [shown in Figs. $5(\mathrm{~d})$ and $6(\mathrm{~d})$ ] and that aggregate along the grain boundaries, mostly have sharp edges and corners which cause high stress concentration. Therefore, for the alloy with $0.10 \mathrm{wt} . \% \mathrm{Ti}$, a sharp decrease in ultimate tensile strength, elongation and charpy impact properties of $9 \%, 30 \%$ and $43 \%$, respectively, in comparison to ASTM A128 Gr. E1 steel is observed. There is no significant difference in yield strength and hardness with increase of Ti from $0.05 \%$ to $0.10 \%$.

One of the most significant results in this study is that $0.05 \%$ Ti addition strikingly decreases the wear rates of solution annealed alloys, especially for high stress wear conditions as shown in Fig. 8. One reason is that $\mathrm{Ti}(\mathrm{CN})$ precipitates provide heterogeneous nuclei during solidification ${ }^{[4,20]}$. This results in grain refinement in general, and also prohibits grain growth during solution annealing. Also, $\mathrm{Ti}(\mathrm{CN})$ particles provide nucleation sites for phosphorus eutectics as can be seen in Fig. 4, which decreases the phosphorus eutectics on

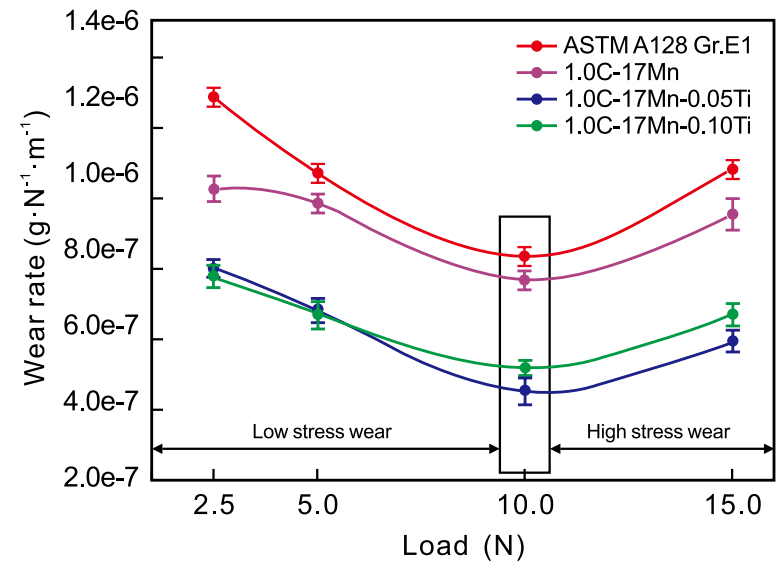

Fig. 8: Wear rate of solution annealed alloys as a function of various loads 
grain boundaries and around carbides ${ }^{[19]}$. The other reason is that $\operatorname{Ti}(\mathrm{CN})$ particles are hard, which increase the surface hardness. However, as can be seen in Figs. 6(c) and (d), when the titanium content increases from $0.05 \%$ to $0.10 \%$, $\mathrm{Ti}(\mathrm{CN})$ particles segregate and cluster. Instead of homogenously dispersed hard particles, clustered particles cause increase in wear rates.

\section{Conclusions}

Microstructural modification and, as a consequence, improvement of mechanical properties of high Mn steels, which have a very wide application fields, is very important. In this study, the effects of Mn and Ti addition on microstructure and mechanical properties of as-cast and solution annealed ASTM A128 Gr. E1 steel were investigated. Especially as a result of the addition of titanium at an optimized rate, it was determined that:

(1) The combination of fine-grain strengthening, solid solution strengthening and dispersion strenthening results in a significant increase in elongation, hardness, yield and tensile strengths of $30 \%, 31 \%, 8 \%$ and $12 \%$, respectively, beside $9 \%$ decrease in impact toughness in annealed $1.0 \mathrm{C}-17 \mathrm{Mn}-0.05 \mathrm{Ti}$ alloy in comparison to ASTM A128 Gr. E1 steel without Mn and Ti modification.

(2) High friction load wear resistance of solution annealed $1.0 \mathrm{C}-17 \mathrm{Mn}-0.05 \mathrm{Ti}$ alloy increases up to $44 \%$ in comparison to ASTM A128 Gr. E1 steel.

When improving the wear resistance of high manganese austenitic steels, it is also very important to increase the tensile strength and elongation without causing a significant decrease in impact strength. In this study, the $1.0 \mathrm{C}-17 \mathrm{Mn}-0.05 \mathrm{Ti}$ alloy can be used for materials exposed to high load wear and applied in the conditions where relatively higher tensile properties with sufficent ductility are needed.

\section{References}

[1] Dalai R, Das S, Das K. Effect of thermo-mechanical processing on the low impact abrasion and low stress sliding wear resistance of austenitic high manganese steels. Wear, 2019, 420-421: 176-183.

[2] Bal B. A study of different microstructural effects on the strain hardening behavior of Hadfield steel. Int. J. Steel Struct., 2018, 18(1): 13-23.

[3] Tüfenk, E. Investigation of austenitic manganese steel with various chemical composition after heat treatment. Master dissertation, Samsun, Ondokuz Mayıs University, Turky, 2012. (In Turkish)

[4] Zhuang W W, Zhi H X, Liu H D, et al. Effect of titanium alloying on the microstructure and properties of high manganese steel. E3S Web Conf., 2019, 79, 01001: 1-6.

[5] Tęcza G, Klempka A G. Microstructure of cast high-manganese steel containing titanium. Arch. Foundry Eng., 2016, 16(4): 163-168.

[6] Cao J L, Zhao A M, Liu J X, et al. Effect of $\mathrm{Nb}$ on microstructure and mechanical properties in non-magnetic high manganese steel. J. Iron Steel Res. Int., 2014, 21(6): 600-605.
[7] Pham M K, Nguyen D N, Hoang A T. Influence of vanadium content on the microstructure and mechanical properties of high-manganese steel. Int. J. Mech. Mechatronics Eng., 2018, 18(2): 141-147.

[8] Agunsoye $\mathrm{J} \mathrm{O}$, Isaac T S, Abiona A A. On the comparison of microstructure characteristics and mechanical properties of high chromium white iron with the Hadfield austenitic manganese steel. J. Miner. Mater. Char. Eng., 2016, 1(1): 24-28.

[9] Cuddy $L \mathrm{~J}$ and Raley $\mathrm{J} C$. Austenite grain coarsening in microalloyed steels. Metall. Trans. A, 1983, 14(A): 1989-1995.

[10] Enloe C M, Fındley K O, Speer A J G. Austenite grain growth and precipitate evolution in a carburizing steel with combined niobium and molybdenum additions. Metall. Mater. Trans. A, 2015, 46(A): 5308-5328.

[11] Gürol U, Kurnaz S C. Effect of carbon and manganese content on the microstructure and mechanical properties of high manganese austenitic steel. J. Min. Metall. Sect. B - Metall., 2020, 56(2): 171-182.

[12] Najafabadi V N, Amini K, Alamdarlo M B. Investigating the effect of titanium addition on the wear resistance of Hadfield steel. Metall. Res. Technol., 2014, 111(1): 375-382.

[13] Tęcza $G$ and Sobula S. Effect of heat treatment on change microstructure of cast high-manganese hadfield steel with elevated chromium content. Arch. Foundry Eng., 2014, 14(3): 67-70.

[14] Davydov N G, Lyamzin V A. Heat treatment of parts and castings from high manganese steel of type $110 \mathrm{G} 13 \mathrm{~L}$ and its special features. Metal Science and Heat Treatment, 2016, 58(9): 559-561.

[15] Marsano D R. Grain refinement and optimization of hadfield steel casting liners for mineral crushing. Master dissertation, Colorado School of Mines, Colorado, USA, 2000: 60-61.

[16] Lv B, Zhang F C, Li M, et al. Effect of phosphorus and sulfur on the thermoplasticity of high manganese austenitic steel. Mater. Sci. Eng. A, 2010, 527: 4648-5653.

[17] Kim R, Bae C, Ha Y M, et al. Effect of titanium addition on high temperature workability of high manganese austenitic steel. ISIJ International, 2018, 58(3): 535-541.

[18] Astudillo P C, Soriano A F, Osorio G M B, et al. Comparative study of the mechanical and tribological properties of a Hadfield and a Fermanal steel. Hyperfine Interact, 2017, 238(56): 1-12.

[19] Siafakas D, Matsushita T, Lauenstein A, et al. Particles precipitation in Ti- and Al-deoxidized Hadfield steels. Steel Res. Int., 2016, 87(10): 1344-1355.

[20] Turnbull D, Vonnegut B. Nucleation Catalysis. Ind. Eng. Chem., 1952, 44(6): 1292-1298.

[21] Kuyucak S, Zavadil R, Gertsman V. Heat-treatment processing of austenitic manganese steels. In: Proc. 66th World Foundry Congress, İstanbul, Turkey, 6-9 September, 2004.

[22] Wang X J, Sun X J, Song C, et al. Grain size-dependent mechanical properties of a high-manganese austenitic steel. Acta Metall. Sin. (Engl. Lett.), 2019, 32(6): 746-754.

[23] Lee U, Sohn S S, Hong S, et al. Effects of Mn addition on tensile and Charpy impact properties in austenitic Fe-Mn-C-Albased steels for cryogenic applications. Metall. Mater. Trans. A, 2014, 45(A): 5419-5430.

[24] Chen J, Dong F T, Liu Z Y, et al. Grain size dependence of twinning behaviors and resultant cryogenic impact toughness in high manganese austenitic steel. J. Mater. Res. Technol, 2021, 10: 175-187.

[25] Sevsek S, Brasche F, Molodov D A, et al. On the influence of grain size on the TWIP/TRIP-effect and texture development in high-manganese steels. Mater. Sci. Eng. A, 2019, 754: 152-160. 